\title{
Acoustic parameters of begging calls indicate chick body condition in Wilson's storm-petrels Oceanites oceanicus
}

\author{
Anja Gladbach · Christina Büßer · \\ Roger Mundry $\cdot$ Petra Quillfeldt
}

Received: 21 August 2007 / Accepted: 4 August 2008/Published online: 20 September 2008

(C) Japan Ethological Society and Springer 2008

\begin{abstract}
Begging behaviour as a key element in the parent-offspring conflict has been studied in many avian species. These types of studies have nearly exclusively been based on call counts, and it is still not entirely clear whether begging calls themselves contain any information. We studied begging behaviour in Wilson's storm-petrel Oceanites oceanicus, a small procellariiform seabird. This species provides the opportunity to study the signalling value of begging calls in the absence of potentially confounding factors such as nestling competition, previous feeding experiences and predation pressure. We applied a new method using a semi-automatic spectrogram analysis software that measures the acoustic parameters of begging calls. Our analysis revealed that the frequency parameters of begging calls reflect chicks' current body condition, with chicks in poorer condition uttering calls at higher frequencies. Chicks uttering higher pitched calls also received larger meals. Our study shows that certain acoustic
\end{abstract}

A. Gladbach $(\bowtie) \cdot$ C. Büßer

Polar and Bird Ecology Group, Institut für Ökologie,

Friedrich-Schiller-University Jena,

Dornburger Str. 159, 07743 Jena, Germany

e-mail: anja.gladbach@gmx.de

R. Mundry

Institut für Verhaltensbiologie, Freie Universität Berlin,

Haderslebener Str. 9, 12163 Berlin, Germany

R. Mundry

Forschungs- und Technologiezentrum Westküste,

Hafentörn 1, 25761 Büsum, Germany

P. Quillfeldt

Vogelwarte Radolfzell, Max Planck Institute for Ornithology,

Schlossallee 2, 78315 Radolfzell, Germany parameters of begging calls can indicate the state of a chick in Wilson's storm-petrels.

Keywords Begging - Oceanites oceanicus .

Provisioning · Seabirds · Signalling · Wilson's storm-petrel

\section{Introduction}

In every sexual reproducing species, parents and offspring compete over the allocation of scarce resources. Due to unequal genetic interests, different amounts of parental investment are expected to maximize their respective fitness gains (Trivers 1974). For parents, every investment in the current offspring exceeding the optimum may be costly in terms of future survival and reproduction. Young mammals and birds therefore have evolved special behavioural characters to solicit food and care from their parents. This begging behaviour has been studied as a key element in the parent-offspring conflict.

It is still not entirely understood whether begging behaviour consists of signals aimed at manipulating parents to provide more food than they are selected to give or if it contains reliable information regarding condition on which parents can base their decisions to allocate resources. Most studies on begging behaviour have taken place in passeriform birds, and based on the results it may well be that chicks convey information on their nutritional needs (Iacovides and Evans 1998; Kilner and Johnstone 1997; Price and Ydenberg 1995; Redondo and Castro 1992). However, these results were partly clouded by the fact that begging behaviour is also influenced by nestling competition (Neuenschwander et al. 2003; Price 1996), previous feeding experiences (Kedar et al. 2000; Rodriguez-Girones et al. 2002) and predation pressure (Briskie et al. 1999). 
Consequently, whether parents respond to solicitation signals has not yet been resolved. Empirical studies yield equivocal results. Several studies have found that an increase in begging due to increased hunger level does affect the parental allocation of food (Cotton et al. 1996; Granadeiro et al. 2000; Leonard and Horn 2001; Ottosson et al. 1997; Redondo and Castro 1992), while others report that solicitation behaviour either does not convey information or that parents do not or cannot act upon that information (Clark and Lee 1998; Ricklefs 1992).

We studied begging behaviour using Wilson's stormpetrels Oceanites oceanicus as a model organism for parent-offspring communication, with the species' biology enabling the exclusion of the influence of a majority of possibly confounding factors. Being a member of the order Procellariiformes, Wilson's storm-petrels have an obligate clutch size of one; consequently, parent-offspring interactions can be studied in the absence of sibling competition (Quillfeldt 2002). They nest, like most other seabirds, on remote islands and are nocturnal; hence, solicitation behaviour is not obscured by the complexities arising from predation pressure caused by small mammals (Granadeiro et al. 2000) and diurnal predators, such as skuas and gulls. The side of the parents provides a rather simple situation as well. Wilson's storm-petrels are socially and genetically monogamous (Quillfeldt et al. 2001) so that parental investment is not affected by an uncertainty about paternity, which may cause a sex bias in caring (Kokko and Jennions 2003). Both parents share chick feeding and visit the nest only at night. Thus, feeding events are discrete, and if only the first feeding in one night is analysed, any influence of recent feedings on the begging behaviour of the chicks can be excluded. Furthermore, Wilson's stormpetrels nest in burrows, so that adults lack the possibility to assess their chick's state via visual cues. The vocal components of begging behaviour therefore play a major role in the communication between parents and young.

The importance of begging behaviour as a means of providing information about the current nutritional status of chicks has also been recognized in other seabird species (Granadeiro et al. 2000; Harris 1983; Henderson 1975; Iacovides and Evans 1998; Quillfeldt 2002; Quillfeldt et al. 2004), but the mechanisms are still poorly understood. In Cory's shearwater Calonectris diomedea, for example, chicks were observed to decrease their begging rate after receiving supplementary food, whereas food-deprived chicks maintained high levels of begging (Granadeiro et al. 2000). Based on their study of the Manx shearwater Puffinus puffinus, Hamer et al. (1999) suggested that information conveyed by the chick's begging intensity serves to reduce the provisioning rate to well-fed chicks but that parents cannot or do not increase food provisioning to poorly fed chicks.
Chicks of Wilson's storm-petrels use two different begging call types, rhythmic and long calls (Fig. 1). The visual appearance in a spectrogram of long begging calls resembles an inverted U. Rhythmic calls consist of a series of elements rapidly repeated and are used as a contact call when an adult enters the nest or when the chick is handled. Long begging calls are only used in the presence of an adult (Quillfeldt 2002). When an adult arrives in the nest, rhythmic calls are first produced, followed by series of long begging calls. At the end of the begging session rhythmic calling starts again. These call structures resemble others described for procellariiform chicks (Bretagnolle 1996 for the fulmar and albatross groups; Quillfeldt et al. 2004 and Quillfeldt and Masello 2004 for shearwaters). A previous study on Wilson's storm-petrel used parameters based on counts of calls, with call rate and call number as features of begging behaviour. The total number of begging calls contained the most information on chicks' body condition, and parents responded to increased numbers of begging calls by providing larger meals (Quillfeldt 2002).

One problem concerning this approach is that the information about the total number of begging calls does not exist until the end of a begging session. The question arises if begging calls themselves contain information on a chick's body condition which returning adults can assess right after entering the nest, i.e. before starting to feed. One possibility is to analyse acoustic parameters of the single call elements, such as frequency, amplitude and duration (Sacchi et al. 2002). In the present study, we measured acoustic parameters of begging calls. To our knowledge, this is one of the first studies on acoustic features of begging calls in seabirds and one of the few that exist for birds
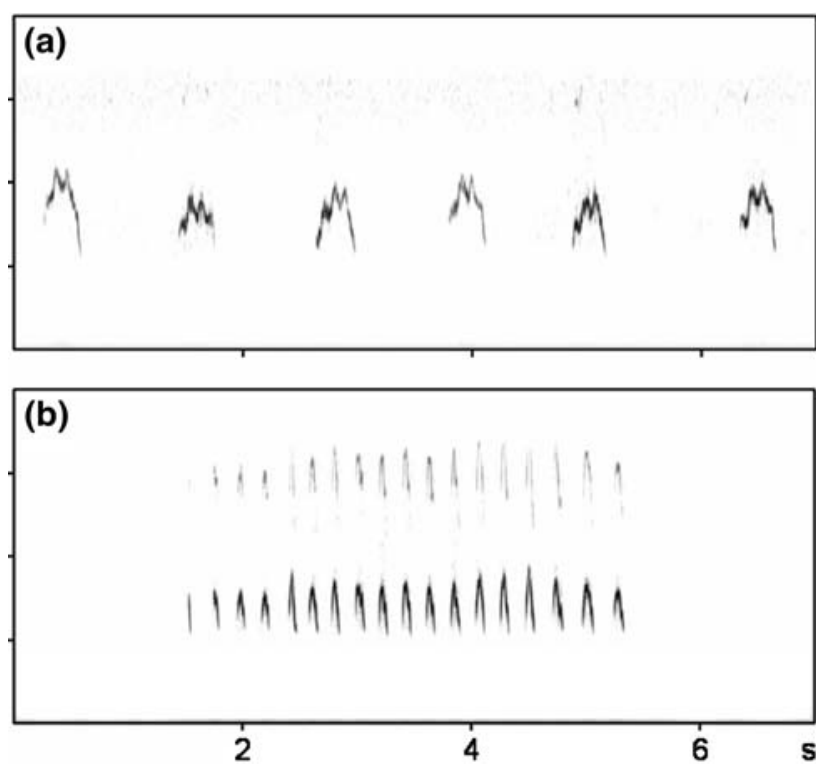

Fig. 1 Sonograms of long begging calls (a) and rhythmic calls (b) of Wilson's storm-petrels (Oceanites oceanicus) 
at all. We tested the following predictions: begging call elements themselves contain information on a chick's state, and parents use those acoustic parameters to adjust their feeding behaviour.

\section{Materials and methods}

Study site and chick measurements

The study was carried out on King George Island, South Shetland Islands $\left(62^{\circ} 14^{\prime} \mathrm{S}, 58^{\circ} 40^{\prime} \mathrm{W}\right)$ in the maritime Antarctic from February 2000 to March 2002. The colony of Wilson's storm-petrels is situated in an area of scree slopes around the extinct volcano Tres Hermanos (Three-Brothers-Hill) and consists of between 1400 and 2200 breeding pairs (Hahn et al. 1998). The first eggs are laid in midDecember, and hatching mainly takes place in the first half of February; the chicks stay in the nest burrows for about 60 days. During the day they are left unattended in the nest, and the adults feed them during nocturnal visits until fledging. Fledging starts during the second half of March.

Nests in the colony were marked and visited daily to weigh chicks (Quillfeldt and Peter 2000). Body mass development was similar for all 3 years of the study. We determined daily body condition (BC) of chicks as the residual mass to the population mean of chicks of the same age (based on body mass data of a total of 144 chicks) following Quillfeldt (2002). Using this method, age is included indirectly into the model and hence controlled for. As a result, body condition is by definition uncorrelated (orthogonal) to age. We included eight chicks aged 0 36 days in the sound analysis (four from the field season, 2000; two from 2001; two from 2002), with body condition ranging from -0.33 to 0.53 ( 0 representing the mean body condition). To be sure that the estimated body condition is not influenced by a recent feeding, we analysed only first feedings in any one night.

Recording of call sessions and analysis of feeding events

We recorded begging calls applying two different methods. In 2000, we used dictaphones placed outside the nest and an external microphone with a 2-m connection in the entrance. Recording was started at dusk and covered $95 \mathrm{~min}$ at low speed (Quillfeldt 2002). In 2001 and 2002, we monitored nest burrows during the night with miniature-infrared cameras that recorded both visual and acoustic information (Masello et al. 2001). To discriminate between adults on the videotapes, we marked one adult of each breeding pair with a dot of paint on the forehead and on the bow of the wing. We started video recording each day at sunset using longplay as recording mode, which enabled $8 \mathrm{~h}$ of filming and thereby covered the whole night.

Adult response to variation in begging intensity was measured as the meal size in the night of recording, following Quillfeldt (2002). We estimated meal sizes from daily mass differences corrected for metabolic mass loss (Quillfeldt and Peter 2000; Ricklefs et al. 1985). We found that meal size is correlated to the age of the chick until 10 days old (Pearson correlation; chicks up to 10 days old: $r_{15}=0.547, \quad P=0.035 ;$ chicks older than 10 days: $r_{54}=0.007, P=0.962$ ). The meal size in very young chicks might be constrained by the ability of the chick to swallow a certain amount of food rather than by the provisioning adult. We therefore only included chicks older than 10 days in the analysis. Meal sizes were defined as one feeding event for weights up to $13 \mathrm{~g}$ and two for weights larger than $13 \mathrm{~g}$ (Obst and Nagy 1993; Quillfeldt and Peter 2000). This method has proved to be accurate in assigning the number of feedings (Büßer 2003). In the case of weights larger than $13 \mathrm{~g}$, the meal size in the first feeding was defined to represent half of the total estimated meal as no other assessment of single meal sizes was possible. In 2001 and 2002, we were able to observe the number of feeding events per night directly on the videotapes. In six cases (out of 57), the number of observed and estimated feeding events differed. We then additionally recorded the meal size in the first feeding resulting from the observation, dividing the total meal size by two if both the male and female fed the chick in one night or assigning meals exceeding $13 \mathrm{~g}$ to the first feeding if only one adult visited the nest. We conducted the statistical analysis for both estimation methods and found no qualitative difference in the results. We therefore present here the results using the more accurate meal size estimation for the seasons 2001 and 2002.

\section{Data analysis}

We defined a begging sessions to start with the first long begging call and to end when rhythmic call series start again without any long begging call following. For all recorded begging sessions, we obtained acoustical parameters of long begging call elements and analysed them using the spectrogram analysis software, ConAn 0.93 (described in Mundry and Sommer 2004). We digitized calls at a sample rate of $16 \mathrm{kHz}$ using CoOL EDIT Pro 2.0 (Adobe Systems, San Jose, CA). We selected between five and 15 calls from the start, middle and end of each feeding session, respectively, for further analysis (differences in number due to very low call rates in some cases).

We produced spectrograms with AviSoFt ver. 4.2. software (AviSoft, Nottingham, UK; FFT-length 512, 
Table 1 Acoustic call parameters of long begging calls of Wilson's storm-petrel chicks (Oceanites oceanicus) calculated using ConAn 0.93 software

\begin{tabular}{lll}
\hline Abbreviation & Call feature & Unit \\
\hline$F_{\text {max }}$ & Maximum frequency of an element & $\mathrm{Hz}$ \\
$F_{\text {mean }}$ & Mean frequency of an element & $\mathrm{Hz}$ \\
SiStMax & Slope of an element from the start to its maximum frequency & $\mathrm{Hz} / \mathrm{ms}$ \\
SiStEnd & Slope of an element from the maximum frequency to the its end & $\mathrm{Hz} / \mathrm{ms}$ \\
LMaxAmp & Location of the maximum amplitude normalized to the element's duration & - \\
LMA_Abs & Location of the maximum amplitude in milliseconds from element's start & $\mathrm{ms}$ \\
PeakFTot & Frequency with the largest amplitude & $\mathrm{Hz}$ \\
\hline
\end{tabular}

resolution: $1 \mathrm{~ms}$, frequency range: $0-8 \mathrm{kHz}$ ) and saved them as .txt-files. ConAn 0.93 uses these files for the semiautomatic analysis of acoustic parameters of the fundamental frequency. The program is able to identify the beginning and end of one element, and if the automatic classification is incorrect, the user can change the thresholds manually. We included seven acoustic parameters in the present analysis (Table 1). As the parameters were measured for each call separately, we calculated median values of the whole begging session per night and chick.

Statistical tests were conducted using SPSS ver. 11.0 (SPSS, Chicago, IL). In order to avoid unreliable assessments of the effects of covariates (see below), we included only those eight chicks into the analysis of which we had obtained recordings of at least four nights. For the analysis of dependency of begging features on body condition, a total of 77 nights could be used, ranging from 4 to 13 nights per chick. For the analysis of effects on meal size, we only included chicks older than 10 days to avoid an underestimation of meal sizes; therefore, a total of 57 nights could be used, ranging from 4 to 13 nights per chick.

Normality was tested using Kolmogorov-Smirnov tests and visually by examining plots of the data. Only one out of the total of nine parameters (body condition, meal size and seven acoustic parameters) differed from normality (LMA_Abs, $z=1.372, n=72, P=0.046$, no a-level adjustment applied), but since a visual inspection of the distribution of this parameter indicated it to be more or less symmetric, we decided to also include this variable without any transformation.

In order to reduce the number of parameters tested we applied a principal component analysis (PCA) with varimax rotation. This procedure was justified, as indicated by the Kaiser-Meyer-Olkin Measure of Sampling Adequacy equalling 0.494 and thus almost reaching the required level (0.5) and Bartlett's test of Sphericity revealing significance $\left(\chi^{2}=475, d f=21, \quad P<0.001 ;\right.$ McGregor 1992). The PCA extracted three factors with eigenvalues in excess of one, together explaining $91.6 \%$ of the total variance. The first factor is mainly correlated to the three parameters of call frequency [maximum frequency $\left(F_{\max }\right)$ and mean
Table 2 Factors extracted by a PCA of begging parameters of Wilson's storm-petrel chicks

\begin{tabular}{lccc}
\hline & \multicolumn{2}{l}{ Factors } & \\
\cline { 2 - 4 } & 1 & 2 & 3 \\
\hline Initial eigenvalues & 3.6 & 1.8 & 1.0 \\
Variance explained by factor $(\%)$ & 51.32 & 25.67 & 14.65 \\
Acoustic call parameters & & & \\
$F_{\text {max }}$ & $0.877^{\mathrm{a}}$ & 0.397 & 0.036 \\
$F_{\text {mean }}$ & $0.966^{\mathrm{a}}$ & 0.157 & 0.006 \\
SlStMax & 0.278 & $0.899^{\mathrm{a}}$ & -0.093 \\
SlMaxEnd & -0.260 & $-0.909^{\mathrm{a}}$ & 0.083 \\
LMaxAmp & -0.136 & 0.020 & $0.954^{\mathrm{a}}$ \\
LMA_Abs & 0.072 & -0.183 & $-0.954^{\mathrm{a}}$ \\
PeakFTot & $0.898^{\mathrm{a}}$ & 0.224 & -0.134 \\
\hline
\end{tabular}

$P C A$ principal component analysis

The upper part of the table (two rows) indicates eigenvalues and the variance explained by each factor. The total (cumulative) variance explained by the three factors was $91.6 \%$. Below, we indicate the rotated component matrix (rotation method: varimax with Kaiser normalization)

${ }^{a}$ Absolute coefficients in excess of 0.5

frequency $\left(F_{\text {mean }}\right)$, frequency with the largest amplitude (PeakFTot)]. The second factor describes the slope of the elements, and the third factor is correlated to the location of the maximum amplitude (Table 2).

We used univariate analyses of covariance (ANCOVA) to test for the influence of body condition on calling and also to test for the influence of calling on meal size. In order to control for individual differences between chicks and avoid pseudoreplication (e.g. Quillfeldt 2002), we included chick as a categorical independent variable ("factor") into these analyses.

We initially tested the relationship between body condition as a covariate and the factor scores obtained from the PCA as the respective response variables as well as the relationship between the factor scores obtained from the PCA as covariates and meal size as the response variable. In addition to the results of these analyses, we report tests of the call parameters correlated to PCA factor 1 itself to enable easier interpretation. 
We also initially included the interaction between the factor "chick" and the covariate into the models. Since, with one exception (see below), this interaction was clearly non-significant $(P>0.25)$, we removed it from the models and indicate the results of these ANCOVA throughout. However, in the case of PCA factor 3, the interaction between chick and the respective covariate was not clearly non-significant $(P<0.25)$ and, therefore, we refrained from using an ANCOVA and instead calculated Pearson's correlation between the two variables, separately for each subject. We then tested whether the population of Pearson's correlations differed from 0 using a $t$-test. We additionally report the average correlation coefficient as an additional indicator of the degree and the direction of the relation between the covariate and the response variable.

As a measure of effect sizes, we included partial $\eta^{2}$-values in the tables (i.e. the proportion of the effect + error variance that is attributable to the effect). The sums of the partial $\eta^{2}$-values are not additive (http://web.uccs.edu/lbecker/ SPSS/glm_effectsize.htm). When using a $t$-test of correlation coefficients, we report the average coefficient of determination (correlation coefficient squared) as a measure of effect size.

When several tests of a single null-hypothesis were carried out, we added alpha-level adjustments as follows: we corrected significant $P$ values for the number of tests, applying the following equation $P_{\text {corr }}=1-\left(1-\alpha^{\prime}\right)^{k}$, which we derived from the conversion of the Dunn-Šidák method (Sokal and Rohlf 1995). In this equation, $P_{\text {corr }}$ denotes the corrected $P$ value, $\alpha^{\prime}$ equals the originally derived $P$ value and $k$ equals the number of tests. Note that $P$ values were not corrected in the case of the call parameters correlated to PCA factor 1 as they are only reported as post-hoc tests, thereby allowing easier interpretation.

\section{Ethical note}

We recorded chick calls without any detectable influence on the birds. The recorders were situated outside the nest burrows, and only a small microphone or miniature camera was placed in the nest. Chicks were weighed during the day, when an adult did not attend the nest, and no desertion occurred. The chicks were caught by hand, and the amount of regurgitated stomach oil was minimal.

\section{Results}

Begging call descriptives

The $F_{\max }$ ranged from 2400 to $4820 \mathrm{~Hz}$ (mean $3500 \pm 390 \mathrm{~Hz}$ ), and the $F_{\text {mean }}$ ranged from 2130 to
$4020 \mathrm{~Hz}$ (mean $3060 \pm 280 \mathrm{~Hz}$ ). The mean slope from the start of an element to its $F_{\max }$ was $8.1 \pm 4.0 \mathrm{~Hz} / \mathrm{ms}$ (range 2.7-30.2 Hz/ms), and the mean slope from the $F_{\max }$ to the end of an element was $-8.5 \pm 3.3 \mathrm{~Hz} / \mathrm{ms}$ (range -22.5 to $-3.0 \mathrm{~Hz} / \mathrm{ms}$ ). The maximum amplitude (LMA_Abs) was reached $116 \pm 63 \mathrm{~ms}$ after the beginning of an element (range 13-401 ms) or, when expressed relative to an element's duration (LMaxAmp), at $0.56 \pm 0.19 \mathrm{~ms}$ (range 0.10-0.97. The PeakFTot ranged from 2133 to $4690 \mathrm{~Hz}$ (mean $3080 \pm 330 \mathrm{~Hz}$ ).

Acoustic parameters and body condition

The frequency parameters of calls reflected a chick's body condition, with chicks in poorer state uttering calls with higher frequencies (Table 3). Factor scores of the first principal component and the PeakFTot, one of the three frequency parameters with the strongest loading on this factor, negatively covaried with body condition (Table 3; Fig. 2).

There was no effect of body condition on the factor scores of the second and third principal component, i.e. neither in relation to the parameters of the slope nor to the

Table 3 Within-chick effects of chick body condition on call parameters of Wilson's storm-petrel chicks and corresponding factors derived from a PCA

\begin{tabular}{|c|c|c|c|c|c|}
\hline Covariate & $\begin{array}{l}\text { Test } \\
\text { statistic }^{\mathrm{a}}\end{array}$ & $\begin{array}{l}\text { Average } \\
\text { rho }^{\text {b }}\end{array}$ & $P$ value & $P_{\text {corr }}{ }^{\mathrm{c}}$ & $\begin{array}{l}\text { Effec } \\
\text { size }^{d}\end{array}$ \\
\hline $\mathrm{CA} \mathrm{f}$ & $7.070\left(F_{1,7}\right)$ & 0.070 & 0.010 & $0.029^{*}$ & 0.10 \\
\hline PCA f & $1.117\left(F_{1,7}\right)$ & .236 & 0.295 & 0.649 & 0.018 \\
\hline PCA factor 3 & $0.562\left(t_{7}\right)$ & 0.085 & 0.592 & 0.932 & 0.168 \\
\hline (1) $F_{\max } \mathrm{e}^{\mathrm{e}}$ & $3.678\left(F_{1,7}\right)$ & -0.305 & 0.060 & & 0.056 \\
\hline (2) $F_{\text {mean }} \mathrm{e}^{\mathrm{e}}$ & $3.259\left(F_{1,7}\right)$ & -0.215 & 0.076 & & 0.050 \\
\hline (3) PeakFTot $^{\mathrm{e}}$ & $7.284\left(F_{1,7}\right)$ & -0.360 & $0.009^{*}$ & & 0.105 \\
\hline
\end{tabular}

The relation between body condition (response variable) and a factor or a parameter (covariate) was either tested using an ANCOVA, including chick as a factor or, in the case of a significant interaction between the covariate and the response variable, using a one-sample $t$ test comparing correlation coefficients, calculated for each chick separately, with the expected average (0)

* Significant $P$ values

a The test statistic indicates the result of the test, the test itself (ANCOVA or $t$ test, respectively) and appropriate degrees of freedom

b Average rho indicates the average correlation between the covariate and body condition, calculated separately for each chick

${ }^{c} P_{\text {corr }}$ indicates $P$ values corrected for the number of tests (i.e. three for the PCA factor scores)

${ }^{\mathrm{d}}$ Effect sizes denote either partial $\eta^{2}$ in the case of an ANCOVA being conducted, or the average of squared correlation coefficients

e Parameters 1-3 correspond to the acoustic parameters strongest correlated to PCA factor 1 

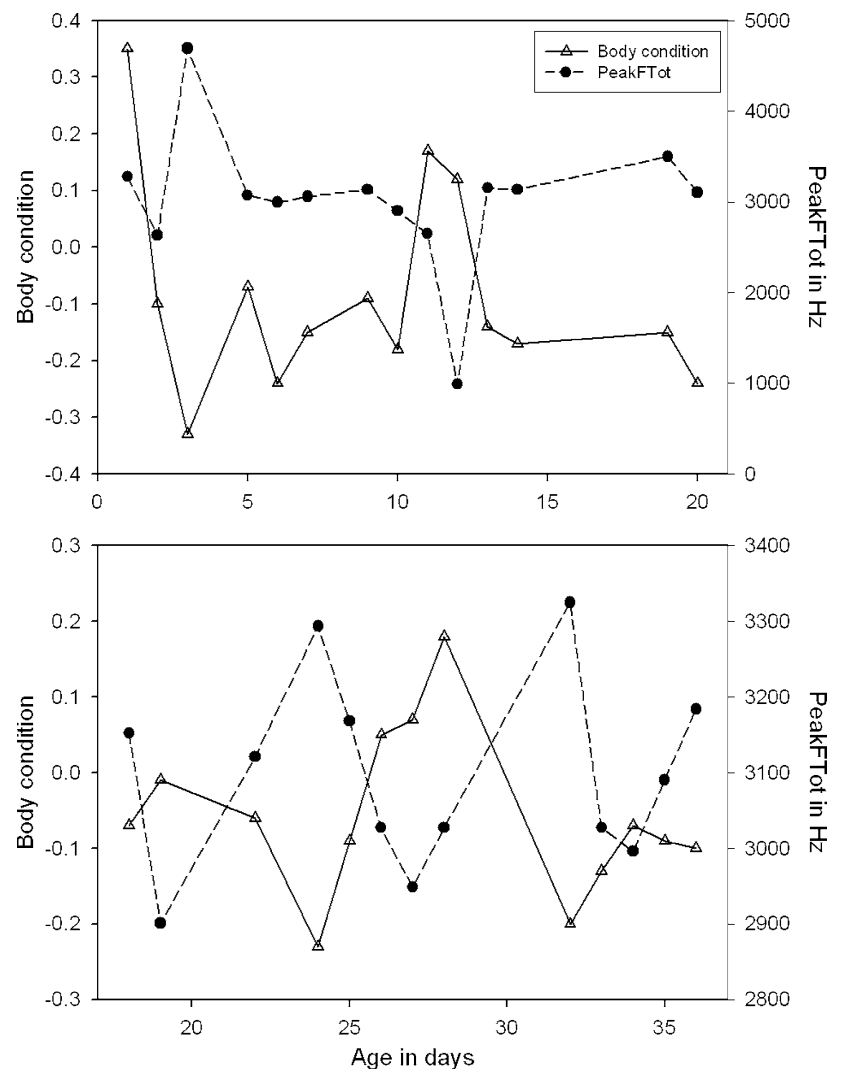

Fig. 2 Examples of the reverse variation in the peak frequency (PeakFTot) of long begging calls and the body condition of Wilson's storm-petrel chicks over time. Open symbols body condition, filled symbols PeakFTot

parameters of location of the largest amplitude within a call.

\section{Acoustic parameters and meal size}

Chicks uttering calls with higher frequencies received larger meals in the night of recording (Table 4). The factor scores of the first principal component as well as two of the three frequency parameters that correlated strongest to this factor $\left(F_{\max }\right.$ and $\left.F_{\text {mean }}\right)$ positively covaried with meal size (Table 4, Fig. 3). However, effect sizes in all these cases were considerably small $(<0.1)$, suggesting only minor biological effects.

\section{Discussion}

We found that some acoustic parameters of begging calls contain information about a chick's state and that in some cases parents seemed to regulate the meal size they provided as a result of a variation in these parameters. As parents regurgitate food from their stomachs to feed the chick, only part of the food may be regurgitated if the chick
Table 4 Within-chick effects of call parameters or corresponding factors derived from a PCA (as covariate) on the meal size in the night of recording (as the response variable) in Wilson's storm-petrels

\begin{tabular}{llcccl}
\hline Covariate & $\begin{array}{l}\text { Test } \\
\text { statistic }\end{array}$ & \multicolumn{1}{l}{$\begin{array}{l}\text { Average } \\
\text { rho }\end{array}$} & $P$ value & $P_{\text {corr }}$ & $\begin{array}{l}\text { Effect } \\
\text { size }\end{array}$ \\
\hline PCA factor 1 & $4.426\left(F_{1,7}\right)$ & 0.423 & $0.041^{*}$ & 0.118 & 0.084 \\
PCA factor 2 & $0.021\left(F_{1,7}\right)$ & -0.195 & 0.884 & 0.998 & 0.000 \\
PCA factor 3 & $1.451\left(t_{7}\right)$ & 0.202 & 0.190 & 0.468 & 0.176 \\
(1) $F_{\text {max }}$ & $4.493\left(F_{1,7}\right)$ & 0.402 & $0.039^{*}$ & 0.086 \\
(2) $F_{\text {mean }}$ & $4.293\left(F_{1,7}\right)$ & 0.424 & $0.044^{*}$ & 0.082 \\
(3) PeakFTot & $3.172\left(F_{1,7}\right)$ & 0.352 & 0.081 & 0.062 \\
\hline
\end{tabular}

For a description of the test procedure and explanation of the abbreviations, headers, etc. see Tables 1 and 3

* Significant $P$ values
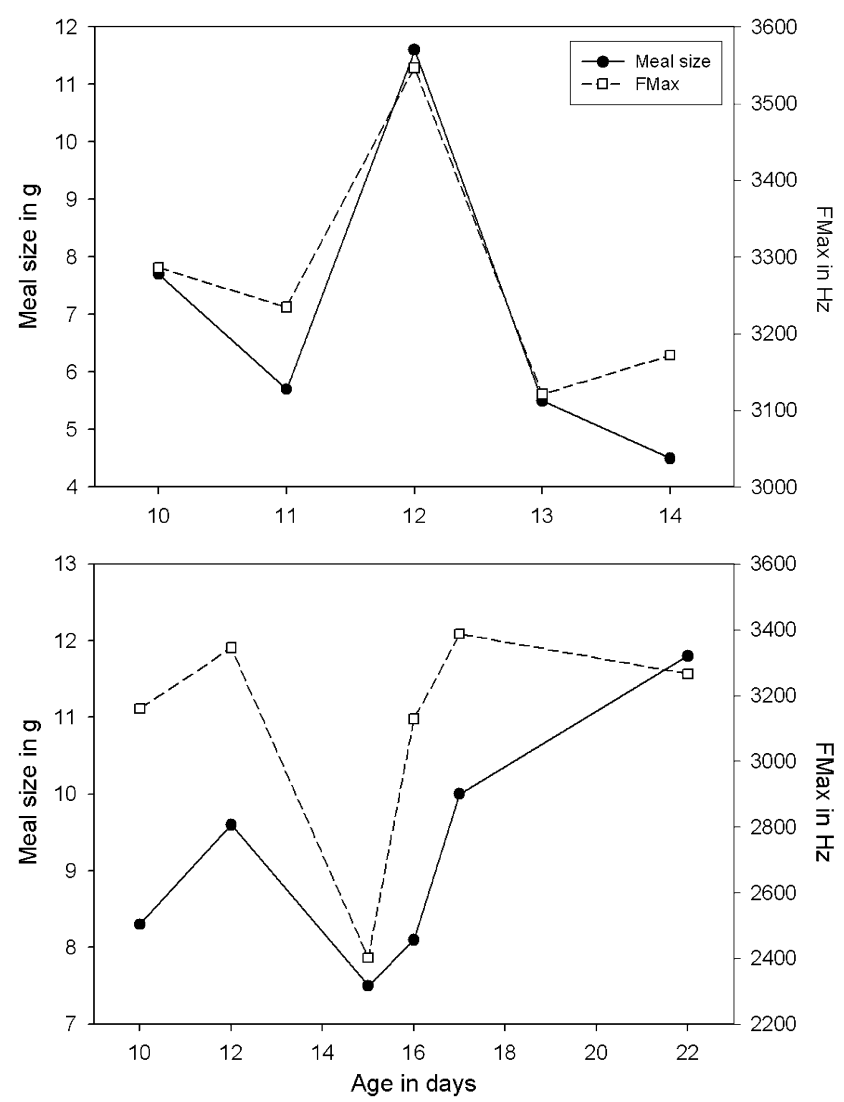

Fig. 3 Examples of the variation in the maximum frequency $\left(F_{\max }\right)$ of long begging calls of Wilson's storm-petrel chicks and the response of the parents in their provided meal size over time. Open symbols $F_{\max }$, filled symbols meal size

is well fed. Begging calls of chicks in a relatively poor state were higher pitched. In a study on Barn swallows Hirundo rustica, Sacchi et al. (2002) showed that body mass and body condition were predicted by the peak frequency (i.e. the PeakFTot in our study), with nestlings in poor condition vocalizing at relatively high frequencies. Of particular 
interest is the fact that the same relationship between the peak frequency and body condition of chicks was found in both a passeriform and a procellariiform bird. Highfrequency values may provide parents with a quick and reliable assessment of a chick's state. In contrast, a study on Cory's shearwater did not find acoustic parameters of begging calls related to body condition (Trager et al. 2006). However, the shape of the begging calls of Cory's shearwaters, with several frequency peaks in one begging call, differs strongly from the simple shape of Wilson's stormpetrel calls. A study comparing acoustic call parameters from other bird species may give useful clues about the evolution of these begging call parameters. Our study suggests that acoustic features of begging calls themselves may serve as an honest signal of need in Wilson's stormpetrels.

The honesty of begging signals in seabirds has been demonstrated several times (Granadeiro et al. 2000; Quillfeldt 2002; Quillfeldt and Masello 2004; Quillfeldt et al. 2004) and may be related to the temporal and spatial unpredictability of food resources in a marine environment. Adult Wilson's storm-petrels have to deal with the same problem concerning their feeding decisions as other seabirds. They are feeding independently of each other and return to the nest approximately every 2-3 days. In the meantime, the state of their chick has changed in an unknown direction, depending upon whether and how much it was fed by the partner. It is therefore assumed that individual adults base their decisions on the provisioning of a certain amount of food on the information derived from chick begging. As predicted by parent-offspring conflict theory (Trivers 1974), parents should avoid allocating more resources than necessary, so that individual parents responding to signals that are most reliable will be evolutionary favoured. Parameters based on call counts (total call number and call rate) were previously shown to strongly covary with chick body condition and with the meal size in Wilson's storm-petrels (Quillfeldt 2002). Due to their relation to body condition, frequency values can also be treated as honest signals in Wilson's storm-petrels.

We also found a weak relation between frequency parameters and the meal size chicks received in the night of recording. Parents seem to respond to high-frequency values in terms of provisioning larger meals. As parents are only responsive to a variation in those acoustic parameters which contain information about the state of their chick, we are optimistic that this weak relationship indicates an actual trend in Wilson's storm-petrels. Our results may partly be clouded by the fact that the meal sizes we used for statistical analysis are based on estimations via measurements of chick body mass. Although this method is correct in indicating the number of feeding events per night, it is not clear what amount of food each parent contributed to the total feeding mass. We are aware that our method of dividing the total meal size equally between the parents may not reflect the actual situation. A system using continuous weighing of the chick would be necessary but is difficult to establish in the field. However, the frequency of calls may be used as an additional indicator of chick condition. This may be especially informative at the beginning of a feeding session, when the total number of calls cannot yet be assessed. In addition, our results need experimental confirmation.

Acknowledgments We would like to thank Hans-Ulrich Peter, Markus Ritz, Isabel Prieto, Tim Janicke and Simone Pfeiffer for their contribution to this work and help during the field season. Two anonymous referees provided comments on the manuscript. Logistical support was provided by the Alfred Wegener Institute for Polar and Marine Research (AWI Bremerhaven, Germany), the National Antarctic Institute of Argentina and Hapag Lloyd Seetouristik GmbH. The study was supported by the Federal Ministry for Education and Research (BMBF CHL 01/016 and CHN 00/031) and partly by the German Science Foundation DFG (PE 454/1ff and Qu148/1).

\section{References}

Bretagnolle V (1996) Acoustic communication in a group of nonpasserine birds, the petrels. In: Kroodsma DE, Miller EH (eds) Ecology and evolution of acoustic communication in birds. Cornell University Press, Ithaka, pp 160-177

Briskie JV, Martin PR, Martin TE (1999) Nest predation and the evolution of nestling begging calls. Proc R Soc Lond B Biol Sci 266:2153-2159

Büßer C (2003) Elterliche Investition und Morphometrie der Buntfußsturmschwalbe, Oceanites oceanicus, auf King George Island, Südshetland-Inseln, Antarktis. Diploma thesis. FriedrichSchiller-University, Jena

Clark AB, Lee WH (1998) Red-winged blackbird females fail to increase feeding in response to begging call playbacks. Anim Behav 56:563-570

Cotton PA, Kacelnik A, Wright J (1996) Chick begging as a signal: are nestlings honest? Behav Ecol 7:178-182

Granadeiro JP, Bolton M, Silva MC, Nunes M, Furness RW (2000) Responses of breeding Cory's shearwater, Calonectris diomedea, to experimental manipulation of chick condition. Behav Ecol 11:274-281

Hahn S, Peter HU, Quillfeldt P, Reinhardt K (1998) The birds of the Potter Peninsula, King George Island, South Shetland Islands, Antarctica, 1965-1998. Mar Ornithol 26:1-6

Hamer KC, Lynnes AS, Hill JK (1999) Parent-offspring interactions in food provisioning of Manx shearwaters: implications for nestling obesity. Anim Behav 57:627-631

Harris MP (1983) Parent-young communication in the Puffin, Fratercula arctica. Ibis 125:109-114

Henderson BA (1975) Role of chicks begging behavior in regulation of parental feeding behavior of Larus glaucescens. Condor 77:488-492

Iacovides S, Evans RM (1998) Begging as graded signals of need for food in young ring-billed gulls. Anim Behav 56:79-85

Kedar H, Rodriguez-Girones MA, Yedvab S, Winkler DW, Lotem A (2000) Experimental evidence for offspring learning in parentoffspring communication. Proc $\mathrm{R}$ Soc Lond B Biol Sci 267:1723-1727 
Kilner R, Johnstone RA (1997) Begging the question: are offspring solicitation behaviours signals of needs. Trends Ecol Evol 12:11-15

Kokko H, Jennions M (2003) It takes two to tango. Trends Ecol Evol 18:103-104

Leonard ML, Horn AG (2001) Begging calls and parental feeding decisions in Tree swallows, Tachycineta bicolor. Behav Ecol Sociobiol 49:170-175

Masello JF, Pagnossin GA, Palleiro GE, Quillfeldt P (2001) Use of miniature security cameras to record behaviour of burrownesting birds. Vogelwarte 41:150-154

McGregor PK (1992) Quantifying responses to playback: one, many, or composite multivariate measures? In: McGregor PK (ed) Playback and studies of animal communication. Plenum Press, New York, pp 79-96

Mundry R, Sommer C (2004) Tonal vocalizations in a noisy environment: an approach to their semi-automatic analysis and examples of its application. An Acad Bras Cienc 76:284-288

Neuenschwander S, Brinkhof MWG, Kölliker M, Richner H (2003) Brood size, sibling competition, and the cost of begging in Great tits, Parus major. Behav Ecol 14:457-462

Obst BS, Nagy KA (1993) Stomach oil and the energy budget of Wilson's storm-petrel nestlings. Condor 95:792-805

Ottosson U, Backman J, Smith HG (1997) Begging affects parental effort in the Pied flycatcher, Ficedula hypoleuca. Behav Ecol Sociobiol 41:381-384

Price K (1996) Begging as competition for food in yellow-headed blackbirds. Auk 113:963-967

Price K, Ydenberg R (1995) Begging and provisioning in broods of asynchronously-hatched yellow-headed blackbird nestlings. Behav Ecol Sociobiol 37:201-208

Quillfeldt P (2002) Begging in the absence of sibling competition in Wilson's storm-petrels, Oceanites oceanicus. Anim Behav 64:579-587
Quillfeldt P, Masello JF (2004) Context-dependent honest begging in Cory's shearwaters, Calonectris diomedea-influence of food availability. Acta Ethol 7:73-80

Quillfeldt P, Peter HU (2000) Provisioning and growth in chicks of Wilson's storm-petrels, Oceanites oceanicus, on King George Island, South Shetland Islands. Polar Biol 23:817-824

Quillfeldt P, Schmoll T, Peter HU, Epplen JT, Lubjuhn T (2001) Genetic monogamy in Wilson's storm-petrel. Auk 118:242-248

Quillfeldt P, Masello JF, Hamer KC (2004) Sex differences in provisioning rules and honest signalling of need in Manx shearwaters, Puffinus puffinus. Anim Behav 68:613-620

Redondo T, Castro F (1992) Signalling of nutritional need by magpie nestlings. Ethology 92:193-204

Ricklefs RE (1992) The roles of parent and chick in determining feeding rates in Leach's storm-petrel. Anim Behav 43:895-906

Ricklefs RE, Day CH, Huntington CE, Williams JB (1985) Variability in feeding rate and meal size of Leach's storm-petrel at KentIsland, New Brunswick. J Anim Ecol 54:883-898

Rodriguez-Girones MA, Zuniga JM, Redondo T (2002) Feeding experience and relative size modify the begging strategies of nestlings. Behav Ecol 13:782-785

Sacchi R, Saino N, Galeotti P (2002) Features of begging calls reveal general condition and need of food of Barn swallow, Hirundo rustica, nestlings. Behav Ecol 13:268-273

Sokal RR, Rohlf FJ (1995) Biometry. W.H. Freeman \& Company, New York

Trager I, Masello JF, Mundry R, Quillfeldt P (2006) Do acoustic parameters of begging calls of Cory's shearwaters Calonectris diomedea reflect chick body condition? Waterbirds 29:315-320

Trivers RL (1974) Parent-offspring conflict. Am Zool 14:249-264 